\title{
Flu pandemic prompts other vaccination delays
}

$\mathrm{N}$ va Scotia is deferring by a year its human papillomavirus and meningococcal $\mathrm{C}$ vaccination program for grade 7 students to free human resources to administer the pandemic (H1N1) 2009 vaccine. Next year, the province will catch up by providing the vaccines to students in grade 7 and grade 8 .

'It's not ideal, but in times of crisis you have to make some difficult prioritization decisions," says Dr. Robert Strang, the province's chief public health officer. "All provinces are taking a critical look at all their programs and doing the same thing we have done: determining what can they defer or delay or do in a different way."

Indeed, health officials in many provinces are concerned about lacking the necessary human resources to administer the H1N1 vaccine during this fall's flu season. It is estimated that as many as 25 million Canadians will receive the vaccine. According to Canada's Chief Public Health Officer, Dr. David Butler-Jones, health care workers may be administering 3.5 million doses a week.

Some have suggested enlisting nurses and physicians outside the public health field, as well as paramedics, to administer the vaccine. Alberta and British Columbia are considering allowing pharmacists to provide $\mathrm{H} 1 \mathrm{~N} 1$ shots.

"We see no reason in British Columbia why we shouldn't be able to deliver the vaccine and if necessary bring in people from other parts of the health care system to help deliver this without compromising other programs," says Dr. Perry Kendall, provincial health officer for British Columbia. "On the other hand, if you have to put a program off for a couple of months, that wouldn't be a big deal."

Ontario health officials say they have more than 100000 doctors and nurses who can administer the H1N1 vaccine,

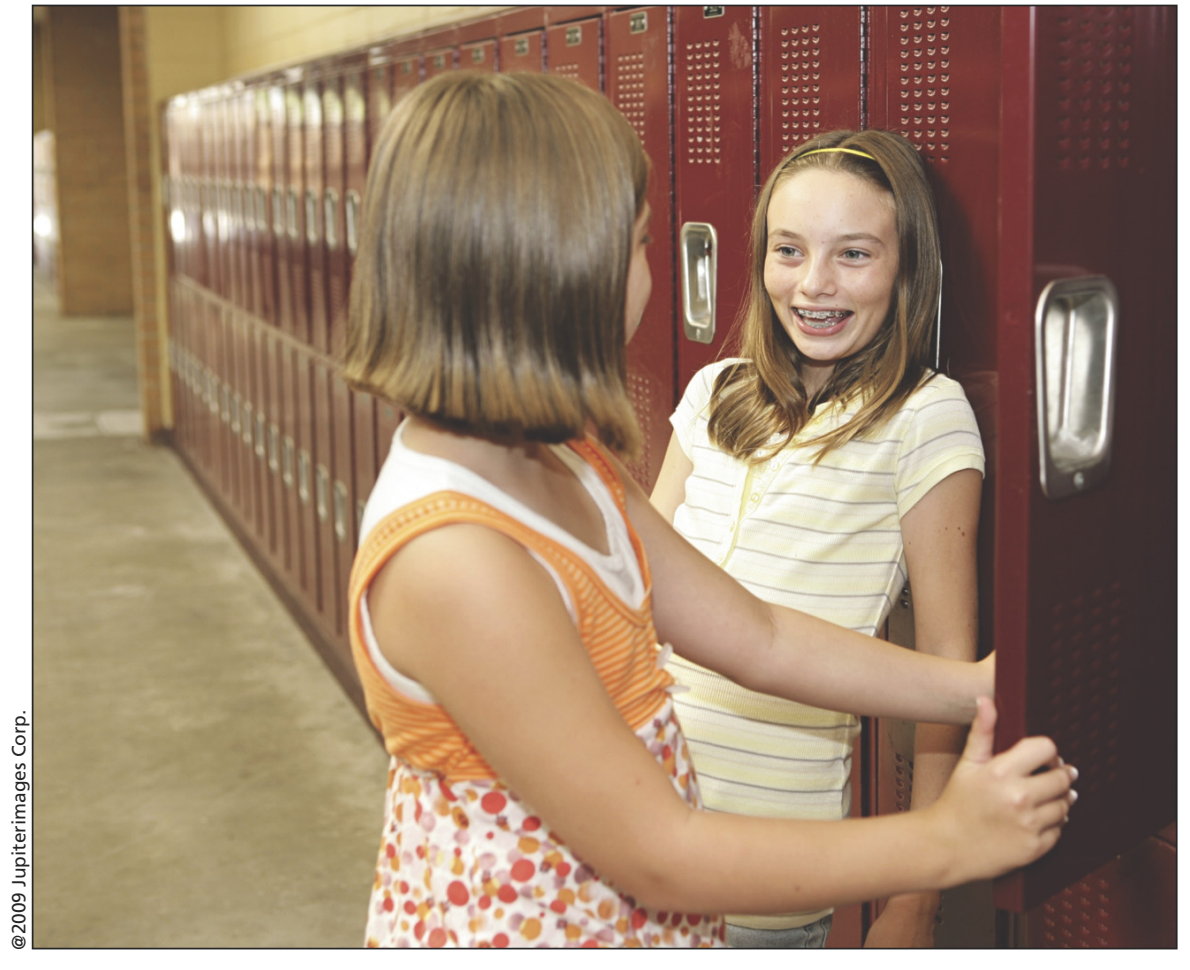

Experts say that deferring vaccines by a year should not pose major health risks for teenagers.

though the province's immunization plan remains a work in progress.

"Ontario has experience in delivering large amounts of seasonal flu vaccine to Ontario's population through its Universal Influenza Immunization Program," David Jensen, a media relations coordinator with Ontario's Ministry of Health and Long-Term Care, writes in an email. "Ontario will be leveraging its experience with this program, with some modifications, to deliver the pandemic H1N1 immunization program. Ontario's goal is to deliver H1N1 vaccine to Ontarians as quickly as possible. Our strategy for administering the H1N1 immunization program is currently under review and development, and will be released once it has been finalized."

Delaying public health initiatives by a year will cause few problems, health experts say, because most of the programs are aimed at long-term issues, such as smoking.

Strang says deferring the human papillomavirus vaccine will increase health risks slightly for the relatively small number of girls who will become sexually active between grades 7 and 8 . But according to Dr. Gerald Evans, president of the Association of Medical Microbiology and Infectious Disease Canada, that's a reasonable measure, considering the risks posed by a potential H1N1 influenza outbreak.

"That, in my mind, is the appropriate utilization of health care," says Evans. "Put off chronic programs to handle the acute issues and get back to the chronic things when you are finished." — Roger Collier, CMAJ

DOI:10.1503/cmaj.109-3043 